\title{
FITODISPONIBILIDADE DE COBRE E PRODUÇÃO DE MATÉRIA SECA POR PLANTAS DE MILHO EM RESPOSTA À APLICAÇÃO DE DEJETOS DE SUÍNOS ${ }^{(1)}$
}

\author{
Edleusa Pereira Seidel ${ }^{(2)}$, Antônio Carlos Saraiva da $\operatorname{Costa}^{(3)} \&$ \\ Maria do Carmo Lana ${ }^{(4)}$
}

\begin{abstract}
RESUMO
Os resíduos da produção de suínos têm grande potencial como condicionadores químicos de solos para a produção vegetal. O objetivo deste trabalho foi avaliar: (a) a produção de matéria seca pela cultura do milho após a adição de dejeto de suínos e de doses crescentes de $\mathrm{Cu}$; (b) como os teores de $\mathrm{Cu}$ e de matéria orgânica no solo podem interferir na absorção e translocação deste elemento para a parte aérea do milho. Este estudo foi realizado em casa de vegetação da Universidade Estadual de Maringá (UEM). O milho foi cultivado em amostra de um Latossolo Vermelho eutroférrico textura argilosa, com dois teores de matéria orgânica (34,09 e $8,60 \mathrm{~g} \mathrm{dm}^{-3}$ provenientes de duas profundidades de coleta). O experimento foi constituído de 14 tratamentos: solo com dois teores de matéria orgânica submetidos a sete tratamentos: testemunha, dejeto de suíno; NPK + dejeto de suíno; NPK + dejeto de suíno $+100 \mathrm{mg} \mathrm{dm}^{-3} \mathrm{de} \mathrm{Cu}$; NPK + dejeto de suíno $+200 \mathrm{mg} \mathrm{dm}^{-3} \mathrm{de} \mathrm{Cu}^{\mathrm{C}}$; $\mathrm{NPK}+$ dejeto de suíno $+300 \mathrm{mg} \mathrm{dm}{ }^{-3} \mathrm{de} \mathrm{Cu}$; NPK + dejeto de suíno $+400 \mathrm{mg} \mathrm{dm}^{-3} \mathrm{de}^{2}$ $\mathrm{Cu}$. A dose de dejeto de suíno aplicada foi igual para todos os tratamentos e equivalente a $120.000 \mathrm{~L} \mathrm{ha}^{-1}$. Constatou-se que o teor de matéria orgânica do solo influenciou na produção de matéria seca da parte aérea do milho. As raízes absorveram parte do excesso de $\mathrm{Cu}$ adicionado, mas não houve translocação do elemento, na mesma proporção, para a parte aérea.
\end{abstract}

Termos de indexação: adubação orgânica, translocação de cobre, metais pesados.

(1) Parte do trabalho de Doutorado desenvolvido no Programa de Pós-Graduação em Solos e Nutrição de Plantas da Universidade Estadual de Maringá - UEM. Recebido para publicação em março de 2009 e aprovado em agosto de 2009.

(2) Professora do Centro de Ciências Agrárias, Universidade do Oeste do Paraná - UNIOESTE-MCR/PR. Rua Marechal Deodoro 376 , CEP 85960-000 Marechal C. Rondon (PR). E-mail: pseidel@unioeste.br

(3) Professor do Departamento de Agronomia, Universidade Estadual de Maringá - MGA/PR. Av. Colombo 5790, Jd. Universitário, CEP 87020-900 Maringá (PR). E-mail: antoniocscosta@gmail.com

(4) Professora do Centro de Ciências Agrárias, Universidade do Oeste do Paraná - UNIOESTE-MCR/PR. Rua Pernambuco 1777, CEP 85960-000 Marechal C. Rondon (PR). E-mail: mclana@unioeste.br 


\title{
SUMMARY: COPPER PHYTOAVAILABILITY AND CORN DRY BIOMASS PRODUCTION AFTER SWINE MANURE APPLICATION
}

\begin{abstract}
The residues of swine production have a great potential as soil chemical conditioners for crop production The purpose of this study was to evaluate: (a) corn yield, after application of swine manure and increasing doses of soluble copper in an Eutroferric Red Latosol with two organic matter contents (34,09 and 8,60 $\left.\mathrm{g} \mathrm{dm}^{-3}\right)$, (b) the influence of soil copper and organic matter content on copper absorption and translocation to corn shoots. The study was set up in a greenhouse of the Universidade Estadual de Maringá, state of Paraná. The soil with two organic matter contents was submitted to seven treatments: control; swine waste; NPK + swine waste; and NPK + swine waste $+100,200,300$ and $400 \mathrm{mg} \mathrm{dm}^{-3}$ copper, respectively. The dose

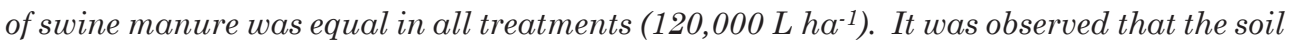
organic matter content influenced the biomass shoot production. Roots absorbed part of the excess copper, but its translocation to the shoot was not proportional.
\end{abstract}

Index terms: organic fertilization, copper translocation, soil copper contamination.

\section{INTRODUÇÃO}

A produção de resíduo rural, principalmente da suinocultura, tem despertado a atenção dos ambientalistas pela alta carga poluidora, especialmente para os recursos hídricos, devido à elevada demanda bioquímica de $\mathrm{O}_{2}(\mathrm{DBO})$ e à presença de metais pesados (Mattias, 2006). A princípio, os dejetos de suínos podem ser considerados condicionadores químicos do solo; todavia, a concentração da aplicação em determinadas áreas pode torná-lo um problema, pois pode haver um desequilíbrio nas relações entre os nutrientes do solo para a maioria das culturas, bem como acúmulo de determinados metais pesados (Basso, 2005; Girotto et al., 2007).

Ultimamente, várias pesquisas vêm sendo realizadas com a finalidade de avaliar a biodisponibilidade de micronutrientes para as culturas após a aplicação de resíduos orgânicos rurais e urbanos (Matos et al., 1996; Amaral Sobrinho et al., 1997; Seganfredo, 2000; Nascimento et al., 2004), bem como avaliar seu potencial de contaminação e poluição.

$\mathrm{O} \mathrm{Cu}$ é um metal pesado e, do ponto de vista ambiental, metal pesado pode ser entendido como aquele que, em determinadas concentrações e tempo de exposição, oferece risco à saúde humana e ao ambiente (Silva et al., 2001; Kabata-Pendias \& Pendias, 2001). A maioria das plantas apresenta um efeito deletério em seu crescimento quando cultivadas em ambiente com excesso desses metais pesados. Esse efeito está relacionado à indução, pelos metais, de distúrbios fisiológicos e nutricionais (Marschner, 1995). Os principais elementos químicos enquadrados neste conceito são: Ag, As, Cd, Co, Cr, Cu, Hg, Ni, Pb, Sb, Se e Zn.
O teor máximo de $\mathrm{Cu}$ a partir do qual há risco para a saúde humana e para o meio ambiente varia muito e depende da legislação de cada país. A legislação dos Estados Unidos, a mais tolerante em relação aos limites, estabelece como teor máximo permitido de $\mathrm{Cu}$ no solo $750 \mathrm{mg} \mathrm{kg}^{-1}$, enquanto a Dinamarca e Suécia, os mais restritivos, exigem $40 \mathrm{mg} \mathrm{kg}^{-1}$ (Seganfredo, 2000). Jackson (1964), citado por Ferreira et al. (2001), estabeleceu o teor total de $\mathrm{Cu}$ nos solos tropicais entre 5 e $40 \mathrm{mg} \mathrm{kg}^{-1}$.

A disposição contínua de dejetos líquidos de suínos, em uma mesma área, pode possibilitar o acúmulo e a contaminação do solo e da água com $\mathrm{Cu}$ (Girotto et al., 2007; Gräber et al., 2005), proveniente em especial de suplementos minerais adicionados à ração.

Segundo Konzen (1983) e Seganfredo (1998), a quantidade de $\mathrm{Cu}$ adicionado por dejetos de suínos a um solo argiloso contendo $30 \mathrm{~g} \mathrm{~kg}^{-1}$ de matéria orgânica é de 271 e $1.113 \mathrm{~g}_{\text {ha }}{ }^{-1}$, respectivamente, e a quantidade extraída de $\mathrm{Cu}$ para a cultura de milho com uma produtividade de $9 \mathrm{t} \mathrm{ha}^{-1}$ é de $24 \mathrm{~g} \mathrm{ha}^{-1}$, o que permite acúmulo desse elemento no solo.

Este trabalho teve por objetivo avaliar a produção de matéria seca pela cultura do milho cultivado em casa de vegetação, após adição de dejetos de suínos, e a contaminação por $\mathrm{Cu}$ em um solo com dois teores de matéria orgânica, bem como avaliar a absorção e a translocação de Cu para a parte aérea da planta.

\section{MATERIAL E MÉTODOS}

Esta pesquisa foi realizada em casa de vegetação, na Universidade Estadual de Maringá, Estado do Paraná. O experimento foi desenvolvido em solo de 
textura argilosa, classificado como Latossolo Vermelho eutroférrico (Embrapa, 2006), coletado no município de Marechal Cândido Rondon, região oeste do Estado do Paraná, em uma área de plantio direto, em duas profundidades (10-20 cm e 100-150 cm). Amostras do solo foram separadas para análise química, determinando-se os teores de matéria orgânica (MO): 34,09 e 8,60 $\mathrm{g} \mathrm{dm}^{-3}$ nessas profundidades, respectivamente. Os teores de MO foram determinados pelo método Walkley \& Black, adaptado por Raij et al. (1987). O N total foi determinado por digestão úmida, método semimicro Kjeldahl, de acordo com o método de Tedesco et al. (1995) (Quadro 1).

O dejeto utilizado foi proveniente de uma granja suinícola, com sistema de criação de engorda, situada no município de Marechal Cândido Rondon, coletado em tanque de estabilização, com tempo de fermentação variando entre 1 e 60 dias. Após cuidadosamente homogeneizado, o material foi coletado e acondicionado em garrafas plásticas e encaminhado para sua caracterização química conforme métodos descritos por Tedesco et al. (1995) (Quadro 2).

$\mathrm{O}$ experimento consistiu de um delineamento inteiramente casualizado $(2 \times 5+4)$, com dois teores de matéria orgânica no solo (34,09 e 8,60 $\left.\mathrm{g} \mathrm{dm}^{-3}\right)$, cinco doses de $\mathrm{Cu}\left(0,100,200,300\right.$ e $\left.400 \mathrm{mg} \mathrm{dm}^{-3}\right)$ na forma de sulfato de $\mathrm{Cu}$, e quatro tratamentos adicionais: tratamento 1 (testemunha); tratamento 2 (dejeto de suíno); tratamento 3 (NPK + dejeto); tratamento $4\left(\mathrm{NPK}+\right.$ dejeto $+100 \mathrm{mg} \mathrm{dm}^{-3}$ de $\left.\mathrm{Cu}\right)$; tratamento $5\left(\mathrm{NPK}+\right.$ dejeto $\left.+200 \mathrm{mg} \mathrm{dm}^{-3} \mathrm{de} \mathrm{Cu}\right)$; tratamento $6\left(\mathrm{NPK}+\right.$ dejeto $\left.+300 \mathrm{mg} \mathrm{dm}^{-3} \mathrm{de} \mathrm{Cu}\right)$; tra- tamento $7\left(\mathrm{NPK}+\right.$ dejeto $\left.+400 \mathrm{mg} \mathrm{dm}^{-3} \mathrm{de} \mathrm{Cu}\right)$. O experimento foi realizado em vasos com capacidade para $5 \mathrm{dm}^{3}$, onde foram colocados $4,8 \mathrm{dm}^{3}$ do solo.

A adubação utilizada no plantio foi equivalente a $10 \mathrm{~kg} \mathrm{ha}^{-1}$ de $\mathrm{N}, 80 \mathrm{~kg} \mathrm{ha}{ }^{-1}$ de $\mathrm{P}_{2} \mathrm{O}_{5}$ e $45 \mathrm{~kg} \mathrm{ha}^{-1}$ de $\mathrm{K}_{2} \mathrm{O}$. Aplicou-se uma dose equivalente a $1 \mathrm{t} \mathrm{ha}^{-1} \mathrm{de}$ calcário em todos os tratamentos 15 dias antes da semeadura. Nos tratamentos que receberam dejeto de suínos, foi adicionado o equivalente a uma dose de 120.000 L ha-1. As unidades experimentais ficaram incubadas por 15 dias. Decorrido o prazo de incubação, fez-se a semeadura do milho híbrido DKB 390, utilizando-se cinco sementes por vaso. Após 15 dias da emergência, foram feitos os desbastes, deixando três plantas por vaso. O experimento foi conduzido por 55 dias após a emergência, quando foram coletadas as plantas de milho, cortadas rentes ao solo, lavadas com água destilada e acondicionadas em sacos de papel. Em seguida, foram levadas para secar em estufa de circulação de ar forçada a $65^{\circ} \mathrm{C}$ por $48 \mathrm{~h}$. Após a secagem, as amostras foram pesadas e moídas para análise do tecido foliar. Foram coletadas, também, as raízes de cada unidade experimental, que foram devidamente lavadas e acondicionadas em sacos de papel e secas em estufa de circulação de ar forçada a $65^{\circ} \mathrm{C}$ por $48 \mathrm{~h}$. Quando as amostras estavam secas, foram pesadas e moídas.

A determinação do $\mathrm{Cu}$ no tecido vegetal foi realizada após digestão nitroperclórica (3:1) (Embrapa, 1997). Em seguida, foram feitas as leituras em espectrofotômetro de absorção atômica modelo GBC932 (Embrapa, 1997). Os dados de matéria seca e o

Quadro 1. Atributos químicos de um Latossolo Vermelho eutroférrico textura argilosa, em duas profundidades, utilizado para cultivo de milho em casa de vegetação

\begin{tabular}{|c|c|c|c|c|c|c|c|c|c|c|c|c|c|c|}
\hline Profundidade & pH CaCl${ }_{2}$ & MO & P mehlich & $\mathrm{Al}^{3+}$ & $\mathrm{H}+\mathrm{Al}$ & $\mathbf{K}^{+}$ & $\mathrm{Ca}^{2+}$ & $\mathrm{Mg}^{2+}$ & SB & CTC & $\mathrm{V}$ & $\mathrm{Zn}$ & $\mathbf{C u}$ & Mn \\
\hline $\mathrm{cm}$ & & $\mathrm{g} \mathrm{dm}^{-3}$ & $\mathrm{mg} \mathrm{dm} \mathrm{m}^{-3}$ & . & 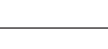 & $-\mathrm{cn}$ & $\mathrm{ol}_{\mathrm{c}} \mathrm{dm}$ & & & & $\%$ & 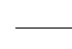 & $\mathrm{ng} \mathrm{kg}^{-1}$ & 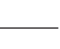 \\
\hline $0-10$ & 5,0 & 34,09 & 5,0 & 0,0 & 4,96 & 0,92 & 6,51 & 2,20 & 9,63 & 14 & 66 & 19,2 & 41,3 & 417 \\
\hline $100-150$ & 5,3 & 8,60 & 3,0 & 0,0 & 3,42 & 0,08 & 2,92 & 1,32 & 7,74 & 11, & 69 & 2,44 & 14,7 & 80 \\
\hline
\end{tabular}

Quadro 2. Caracterização do dejeto de suínos proveniente de uma granja suinícola, com sistema de criação de engorda, situada no município de Marechal Cândido Rondon

\begin{tabular}{|c|c|c|c|c|c|c|c|c|c|c|c|c|c|c|c|}
\hline $\mathrm{pH} \mathrm{H}_{2} \mathrm{O}$ & $\mathbf{M S}^{(1)}$ & $\mathbf{U}^{(2)}$ & $\mathbf{S T}^{(3)}$ & $\mathrm{SV}^{(4)}$ & $\mathrm{N}$ total & $\mathrm{N}-\mathrm{NH}_{4}$ & $\mathrm{~N}-\mathrm{NO}_{3}$ & $\mathbf{P}$ & $\mathrm{Ca}^{2+}$ & $\mathrm{Mg}^{2+}$ & $\mathbf{K}^{+}$ & $\mathbf{F e}$ & $\mathrm{Zn}$ & $\mathrm{Cu}$ & Mn \\
\hline & 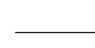 & - $\%$ & 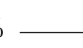 & - & 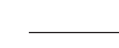 & $-\mathrm{kg} \mathrm{m}^{-3}$ & ـ & 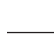 & $-\mathrm{g} \mathrm{d}$ & $n^{-3}$ & - & 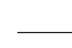 & $-\mathrm{mg}$ & $n^{-3}-$ & 工 \\
\hline 6,8 & 6,9 & 93 & 7 & 74 & 3,0 & 1,8 & 0,05 & 5,4 & 25 & 4,8 & 11,7 & 216 & 17 & 45 & 523 \\
\hline
\end{tabular}


teor de $\mathrm{Cu}$ na parte aérea, nas raízes e no solo foram submetidos à análise de variância, utilizando o software SAEG.

\section{RESULTADOS E DISCUSSÃO}

\section{Matéria seca da parte aérea e das raízes de milho}

A matéria seca da parte aérea (MSPA) e a das raízes (MSRA) da cultura do milho foram significativamente influenciadas pelos teores de $\mathrm{MO}$ e pelas doses de $\mathrm{Cu}$ adicionadas. A interação do teor de matéria orgânica e doses de $\mathrm{Cu}$ foi significativa a $5 \%$ pelo teste $\mathrm{F}$.

Após a análise de variância, foram feitos os desdobramentos para as variáveis produção de MSPA, MSRA, teores de $\mathrm{Cu}$ na parte aérea $(\mathrm{CuPa})$, e teores de $\mathrm{Cu}$ na raiz (CuRA) em função de diferentes doses de $\mathrm{Cu}$ nos tratamentos fatoriais e do teste de médias para os tratamentos adicionais (Quadro 3).

Verificou-se que a maior produção de matéria seca ocorreu no tratamento com maior teor de MO, com exceção da dose equivalente a $100 \mathrm{mg} \mathrm{dm}^{-3}$ de $\mathrm{Cu}$ (Quadro 3). Esta maior produção deve-se principalmente à interferência da matéria orgânica nas propriedades físicas (estrutura, aeração, densidade aparente e retenção de umidade) e químicas do solo (CTC, poder tampão, disponibilidade de nutrientes, Quadro 1) (Canellas et al., 2008).

Quando se comparou o dejeto de suíno com doses de $\mathrm{Cu}$, no tratamento com $34,09 \mathrm{~g} \mathrm{dm}^{-3}$ de $\mathrm{MO}$, constataram-se diferenças significativas nos tratamentos que receberam as maiores doses de $\mathrm{Cu}$ (300 e $400 \mathrm{mg} \mathrm{dm}^{-3}$ ), com as menores produções de
MSPA, talvez devido à fitotoxidade causada pelo elemento (Quadro 3).

Resultados semelhantes foram relatados por Luchese et al. (2004), que constataram diminuição da massa seca da parte aérea de milho em doses crescentes de $\mathrm{Cu}$.

A adição do dejeto nos tratamentos com $34,09 \mathrm{e}$ $8,60 \mathrm{~g} \mathrm{dm}^{-3}$ de MO promoveu aumentos na produção de MSPA em relação à testemunha, demonstrando seu efeito como condicionador do solo, fornecendo nutrientes e atividade biológica ao solo e, portanto, às plantas, conforme demonstrado por Konzen (1983), Scherer et al. (1995) e Seganfredo (2000).

Quando se comparou o dejeto de suíno com doses de $\mathrm{Cu}$, no tratamento com 8,60 $\mathrm{g} \mathrm{dm}^{-3}$ de $\mathrm{MO}$, foram constatadas diferenças significativas apenas nos tratamentos que receberam as doses de $100 \mathrm{e}$ $200 \mathrm{mg} \mathrm{dm}{ }^{-3}$ de $\mathrm{Cu}$, cuja produção de MSPA foi superior à do tratamento que recebeu apenas dejeto de suíno (Quadro 3). Este resultado pode ser explicado pelo fato de neste tratamento o teor de $\mathrm{Cu}$ no solo ser menor que no tratamento com $34,09 \mathrm{~g} \mathrm{dm}^{-3}$ de $\mathrm{MO}$ (Quadro 1). Galrão (1988) e Ferreira et al. (2001) também constataram respostas às adubações com $\mathrm{Cu}$ em cereais, trigo, milho, arroz, aveia e cevada. Os cereais são as culturas mais suscetíveis à deficiência de $\mathrm{Cu}$.

A MSRA para os dois teores de MO foi significativamente diferente em relação à testemunha. O tratamento que recebeu apenas dejeto de suíno quando comparado com doses de $\mathrm{Cu}$ não apresentaram diferenças significativas no tratamento com $34,09 \mathrm{~g} \mathrm{dm}$ 3 de MO, enquanto no tratamento com $8,60 \mathrm{~g} \mathrm{dm}^{-3}$ foram verificadas diferenças significativas nas doses de 200 e $300 \mathrm{mg} \mathrm{dm}^{-3} \mathrm{de} \mathrm{Cu}$.

Quadro 3. Produção de matéria seca da parte aérea (MSPA), teores de Cu da parte aérea (CuPA), matéria seca das raízes (MSRA), teores de cobre das raízes (CuRA) de plantas de milho e teores de cobre no solo (CuSolo), após a adição de diferentes doses de cobre em amostras de Latossolo Vermelho eutroférrico com dois teores de matéria orgânica (coletadas a duas pronfundidades)

\begin{tabular}{|c|c|c|c|c|c|c|c|c|c|c|}
\hline Dose $\mathrm{Cu}$ & MO 34,09 & MO 8,60 & MO 34,09 & MO 8,60 & MO 34,09 & MO 8,60 & MO 34,09 & MO 8,60 & MO 34,09 & MO 8,60 \\
\hline $\mathrm{mg} \mathrm{dm}^{-3}$ & & $\mathrm{~g} / \mathrm{pl}$ & anta & & & & $\mathrm{g} \mathrm{k}^{-1}$ & & $-\mathrm{mg}$ & $m^{-3}-$ \\
\hline 0 & $16,23^{* *}$ & $8,49^{* *}$ & $7,03^{* *}$ & $4,59^{* *}$ & $5,0^{\mathrm{ns}}$ & $5,2^{\mathrm{ns}}$ & $122,07 \mathrm{~ns}$ & $245,24^{* * * \bullet}$ & 42,82 & 15,91 \\
\hline 100 & $14,34^{\text {** }}$ & $17,49^{* * \bullet}$ & $6,89^{* *}$ & $4,29^{\text {** }}$ & $6,1^{\mathrm{ns}}$ & $10,9 * * \bullet$ & $267,40^{* * \bullet}$ & $221,47^{* \bullet}$ & $144,54^{*}$ & 103,32 \\
\hline 200 & $15,09^{* *}$ & $11,00^{* * \bullet \bullet}$ & $7,11^{* *}$ & $5,11^{* * \bullet}$ & $6,3^{\mathrm{ns}}$ & $13,8^{* * \bullet}$ & $339,77 * * \bullet$ & $442,97 * * \bullet$ & 242,86 & 215,89 \\
\hline 300 & $9,29^{* * \bullet}$ & $7,74^{* *}$ & $6,52^{* *}$ & $5,38^{* * *}$ & $8,60^{\mathrm{ns}}$ & $12,1^{* * * \bullet}$ & $445,80 * * \bullet$ & $2057,17^{* * \bullet}$ & 380,34 & 342,72 \\
\hline 400 & $8,97^{* * \bullet}$ & $6,01^{* *}$ & $6,52^{* *}$ & $3,49 * *$ & $6,2^{\mathrm{ns}}$ & $8,5^{\circ}$ & $437,17 * * \bullet$ & $2136,00^{* *} \bullet$ & 502,88 & 469,78 \\
\hline Test. ${ }^{(1)}$ & $5,23 \mathrm{bA}$ & $0,98 \mathrm{bB}$ & $4,63 \mathrm{bA}$ & $0,94 \mathrm{bB}$ & 6,9 aA & $6,8 \mathrm{aA}$ & 81,27 aA & 65,43 aA & 42,69 & 14,18 \\
\hline Dejeto & $14,7 \mathrm{aA}$ & $6,62 \mathrm{aB}$ & $7,16 \mathrm{aA}$ & $3,13 \mathrm{aB}$ & $5,4 \mathrm{aA}$ & $6,1 \mathrm{aA}$ & $120,17 \mathrm{aA}$ & $93,33 \mathrm{aA}$ & 42,59 & 17,28 \\
\hline
\end{tabular}

(1) Médias seguidas da mesma letra minúscula na coluna e maiúscula na linha não diferem entre si pelo teste de Tukey a 1 \%. **, *: comparação entre cada dose de $\mathrm{Cu}$ aplicada no solo em relação à testemunha, pelo teste t, a 1 e 5 \%, respectivamente. .., : comparação entre cada dose de $\mathrm{Cu}$ aplicada no solo em relação à aplicação equivalente de $120.000 \mathrm{~L}^{-1} \mathrm{~d}^{-1}$ de dejeto de suíno, pelo teste t, a 1 e $5 \%$, respectivamente. 
No tratamento com maior teor de MO, a MSPA decresceu linearmente quando foram aumentadas as doses de $\mathrm{Cu}$ no solo (Figura 1). No tratamento com $8,60 \mathrm{~g} \mathrm{dm}^{-3}$ de $\mathrm{MO}$ quando foram aumentadas as doses de $\mathrm{Cu}$, a produção de MSPA apresentou efeito quadrático.

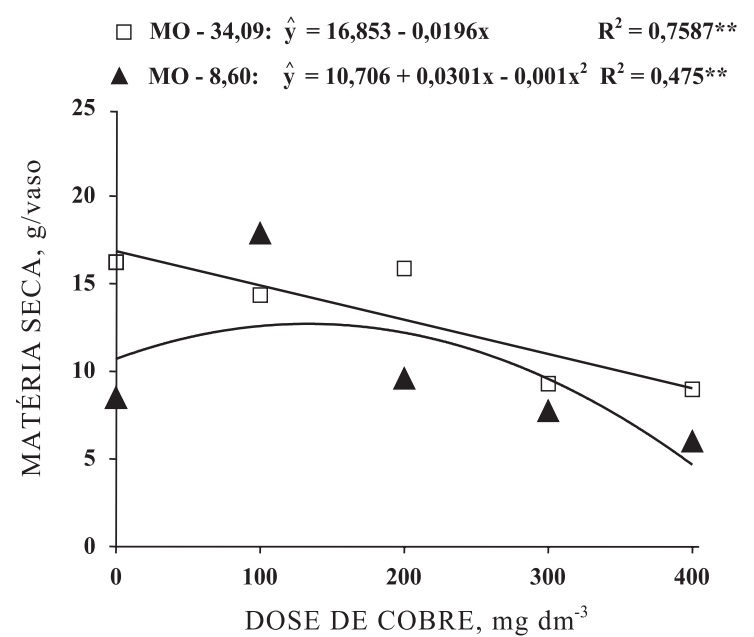

Figura 1. Matéria seca da parte aérea do milho em função de doses de cobre aplicadas em amostras de um Latossolo Vermelho eutroférrico com dois teores de matéria orgânica (duas profundidades de coletas).

\section{Cobre na parte aérea e na raiz de milho}

Os teores de $\mathrm{Cu}$ na parte aérea (CuPA) do milho variaram de 5,0 a $13,80 \mathrm{mg} \mathrm{kg}^{-1}$. Esses teores encontram-se dentro dos intervalos considerados adequados para as plantas de milho, segundo Malavolta et al. (1997) e Raij et al. (1996) - de 6 a $20 \mathrm{mg} \mathrm{kg}^{-1}$ e 50 a $250 \mathrm{mg} \mathrm{kg}^{-1}$, respectivamente. Resultados semelhantes foram encontrados por Anjos \& Mattiazzo (2000), que, após cultivar milho com biossólido proveniente da Estação de Esgotos da SABESP-Barueri, verificaram que os teores de $\mathrm{Cu}$ na planta eram maiores em todas as partes do vegetal, entretanto, na folha diagnose das plantas encontravam-se dentro do intervalo considerado adequado por Malavolta et al. (1997).

De acordo com Ferreira et al. (2001) e Rappaport et al. (1988), a toxicidade de Cu não é comum, mesmo quando o elemento é aplicado em grandes doses. Esses autores não observaram sintomas de fitotoxidade de $\mathrm{Cu}$ em plantas de milho cultivadas com biossólido, mesmo quando as concentrações de $\mathrm{Cu}$ excederam os limites estabelecidos pela legislação.

Foi constatado que, no tratamento com $34,09 \mathrm{~g} \mathrm{dm}^{-3}$ de MO, não houve diferença significativa no teor de $\mathrm{CuPA}$ entre as doses, evidenciando que o $\mathrm{Cu}$ adicionado não foi translocado proporcionalmente para a parte aérea. $\mathrm{O}$ fato de o $\mathrm{Cu}$ não ter sido translocado pode ser devido à capacidade da MO do solo em diminuir sua disponibilidade para a planta, como indicam Dechen \& Nachtigall (2006). Diversos autores também constaram o efeito da MO em diminuir a disponibilidade de $\mathrm{Cu}$ para as plantas devido à formação de complexos estáveis (Stevenson \& Ardakani, 1972; Ferreira et al., 2001; Andreoli, et al., 2003; Martins et al., 2003).

A análise das plantas cultivadas no solo com 8,60 $\mathrm{g} \mathrm{dm}^{-3}$ de MO mostrou que o teor de CuPA foi significativamente maior com as doses de 100, 200 e $300 \mathrm{mg} \mathrm{dm}^{-3}$ quando comparado com o da testemunha (Quadro 3). Neste tratamento, a comparação do teor de $\mathrm{Cu}$ na parte aérea do tratamento que recebeu apenas dejeto de suíno com os demais (doses de $\mathrm{Cu}$ ) apresentou diferenças significativas com as doses de $\mathrm{Cu}$ de 100 , 200, 300 e $400 \mathrm{mg} \mathrm{dm}^{-3}$, que tiveram teores superiores. $\mathrm{O}$ menor teor de MO (solo + dejeto) não foi suficiente para reduzir a disponibilidade deste elemento para a planta, o que permitiu sua maior absorção pela planta. Simonete \& Kiehl (2002) correlacionaram as quantidades de $\mathrm{Cu}$ absorvidas por plantas de milho após aplicação de lodo e observaram aumentos significativos no teor de $\mathrm{Cu}$ nas plantas de milho.

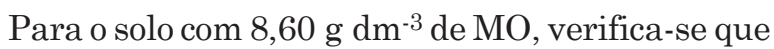
a dose que permite a máxima produção de MSPA é de $224,69 \mathrm{mg} \mathrm{dm}^{-3}$ de $\mathrm{Cu}$; a partir desta dose a produção de MSPA diminuiu (Figura 2). No entanto, no solo com 34,09 $\mathrm{g} \mathrm{dm}^{-3}$, o efeito foi linear crescente no teor de CuPA em função da aplicação das doses crescentes de $\mathrm{Cu}$.

Reddy et al. (1989) e Anjos \& Mattiazzo (2000) constataram aumentos lineares nos teores de $\mathrm{Cu}$ na cultura do milho quando foram aplicadas diferentes doses de biossólidos provenientes de Estações de

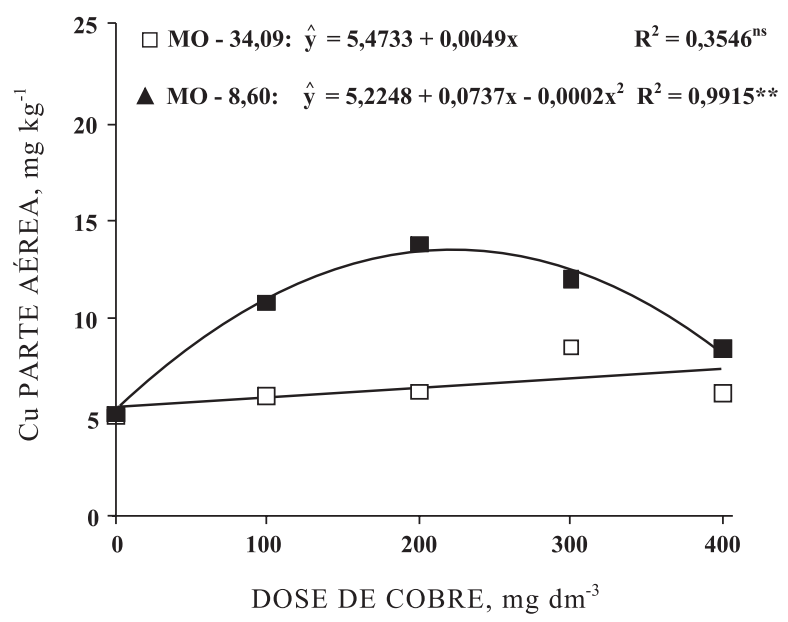

Figura 2. Teores de cobre na parte aérea da planta de milho cultivada em amostras de Latossolo Vermelho eutroférrico (duas profundidades de coleta) após receber doses de cobre e dejeto de suíno. 
Tratamentos de Esgotos (ETE). De acordo com Anjos \& Mattiazzo (2000), o teor de Cu nos grãos de milho variou de 1 a $3 \mathrm{mg} \mathrm{kg}^{-1}$, enquanto nas folhas variou de 13 a $22 \mathrm{mg} \mathrm{kg}^{-1}$.

$\mathrm{Na}$ análise de variância dos teores de Cu nas raízes (CuRA), verificou-se que esses foram influenciados pelos tratamentos nos dois teores de MO. Ao analisar seus desdobramentos (Quadro 3), houve diferenças significativas no teor de $\mathrm{Cu}$ nas raízes entre a testemunha e as doses de $\mathrm{Cu}$ nos dois tratamentos com teores diferentes de MO. Quando aumentaram as doses de $\mathrm{Cu}$ adicionadas no solo, aumentou também o teor de CuRA (Figura 3).

Verificou-se que as raízes absorveram parte do $\mathrm{Cu}$ em excesso aplicado nos tratamentos, mas não houve translocação proporcional para a parte aérea, evidenciando que as raízes de milho possuem mecanismos que impedem a translocação de parte do excedente de $\mathrm{Cu}$ absorvido. De acordo com Silva et al. (2007), as raízes de plantas de arroz e soja limitam a translocação de $\mathrm{Cu}$ para a parte aérea. As raízes das plantas possuem diversos mecanismos de tolerância ao excesso de $\mathrm{Cu}$, como imobilização do $\mathrm{Cu}$ na parede celular, exclusão ou restrição da absorção, compartimentalização no vacúolo com complexos solúveis, formação de quelatos na interface parede celular-membrana e fitoquelatinas, que quelatam metais pesados nas células, evitando danos intracelulares (Marschner, 1995).

Os teores elevados de $\mathrm{Cu}$ nas raízes $(445,8$ e $2135,0 \mathrm{~g} \mathrm{~kg}^{-1}$ ), nos tratamentos que receberam $300 \mathrm{e}$ $400 \mathrm{mg} \mathrm{dm}^{-3}$ de $\mathrm{Cu}$ (Quadro 3), foram suficientes para reduzir a produção de MSPA, provavelmente por danos às membranas das raízes. De acordo com Malavolta et al. (1997), em altos teores de $\mathrm{Cu}$, as raízes funcionam de maneira anormal, pois perdem elementos previamente absorvidos, o que é considerado uma indicação de dano na permeabilidade da membrana.

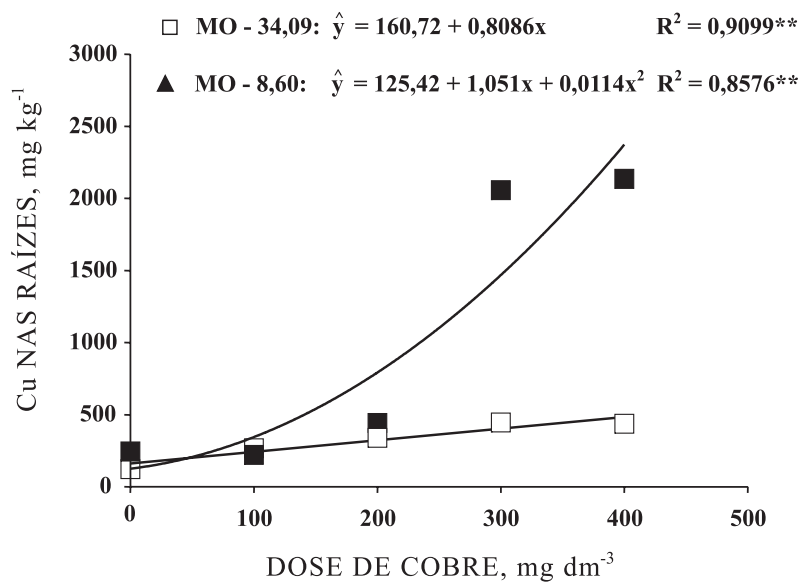

Figura 3. Teores de cobre nas raízes da planta de milho cultivada em amostras de Latossolo Vermelho eutroférrico (duas profundidades de coleta) após receber doses de cobre e dejeto de suíno.
De acordo com Kabata-Pendias \& Pendias (2001), a maioria das espécies pode acumular $\mathrm{Cu}$ especialmente nas raízes. Lavado et al. (2001), pesquisando a absorção de metais pesados e micronutrientes por plantas de milho, concluíram que as raízes das plantas apresentam maior teor de $\mathrm{Cu}\left(48,9 \mathrm{mg} \mathrm{kg}^{-1}\right)$, comparando-as com as folhas, e isso foi relacionado, principalmente, à baixa translocação do $\mathrm{Cu}$ da raiz para parte aérea. A raiz atuou como um filtro natural reduzindo a transferência do metal para o restante da planta.

\section{Cobre no solo após a aplicação de dejeto de suíno}

$\mathrm{Na}$ análise de variância para o teor de Cu no solo, verificou-se que a MO do solo, bem como as doses de $\mathrm{Cu}$ adicionadas, interferiram significativamente nos teores de $\mathrm{Cu}$ do solo disponíveis e a interação $\mathrm{MO}$ e doses de Cu também foi significativa.

No desdobramento da análise de variância, constatou-se que a testemunha e a aplicação de dejeto diferiram dos tratamentos fatoriais (doses de $\mathrm{Cu}$ ), mas não houve diferença significativa entre a testemunha e o tratamento que recebeu apenas dejeto de suíno (Quadro 3).

$\mathrm{O}$ teor de $\mathrm{Cu}$ disponível no solo, em função das doses crescentes de $\mathrm{Cu}$ adicionadas para ambos os tratamentos (34,09 e 8,60 $\mathrm{g} \mathrm{dm}^{-3}$ de MO), teve aumento linear (Figura 4). Verificou-se que apenas com a dose de $100 \mathrm{mg} \mathrm{dm}^{-3}$ o teor de $\mathrm{Cu}\left(103,32 \mathrm{mg} \mathrm{d}^{-3}\right)$ ficou dentro do limites máximos permitidos pela legislação da União Europeia, que é de 50 a $140 \mathrm{mg} \mathrm{kg}^{-1}$, e os demais teores ficaram acima, entretanto abaixo do limite máximo permitido pelo Estados Unidos, que é de $750 \mathrm{mg} \mathrm{kg}^{-1}$ (Seganfredo, 2000) (Quadro 3).

Matos et al. (1996) pesquisaram sobre a retenção dos metais pesados no solo e verificaram que a adsorção

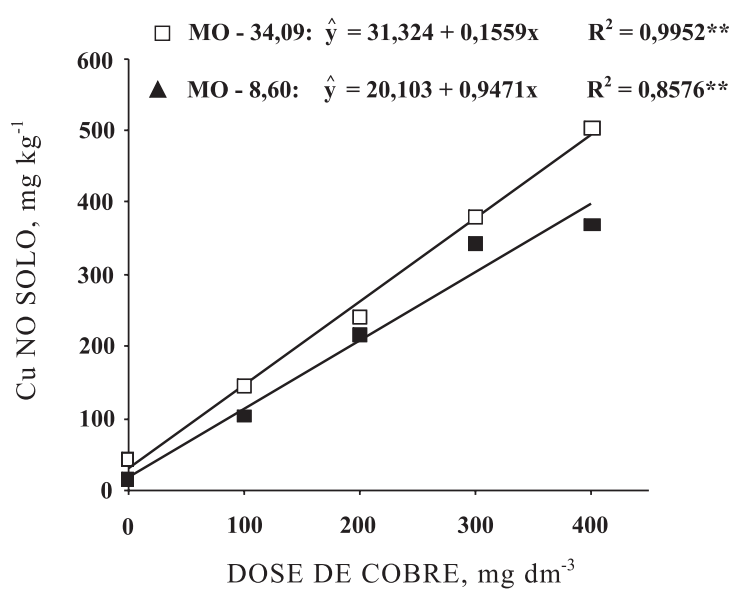

Figura 4. Teores de cobre em amostras de Latossolo Vermelho eutroférrico (duas profundidades de coleta), com dois teores de matéria orgânica, após adição de dejeto de suíno e enriquecimento com sulfato de cobre. 
ocorre nos argilominerais com sítios negativos, onde os metais são adsorvidos por forças eletrostáticas. Além disso, os metais podem ser complexados por compostos orgânicos, adsorvidos ou oclusos em carbonatos ou óxidos de $\mathrm{Fe}, \mathrm{Al}$ e $\mathrm{Mn}$.

\section{CONCLUSÕES}

1. Os teores de matéria orgânica do solo alteraram a produção de matéria seca da parte aérea da cultura do milho; ela foi maior no solo com 34,09 $\mathrm{g} \mathrm{dm}^{-3}$ de matéria orgânica.

2. O maior teor de matéria orgânica no solo reduziu a disponibilidade de $\mathrm{Cu}$ no solo e o teor de $\mathrm{Cu}$ na planta.

3. Os teores de $\mathrm{Cu}$ nas raízes foram maiores, sugerindo menor translocação para a parte aérea.

\section{LITERATURA CITADA}

AMARAL SOBRINHO, N.M.B.; VELLOSO, A.C.X. \& OLIVEIRA, C. Solubilidade de metais pesados em solo tratado com resíduo siderúrgico. R. Bras. Ci. Solo, 21:916, 1997.

ANDREOLI, C.V.; FERREIRA, A.C.; PEGORINI, E.S. \& SOUZA, M.L.P. Efeito da aplicação de lodo de esgoto nos teores de metais pesados de solos, folhas e grãos de milho. In: CONGRESSO BRASILEIRO DE CIÊNCIA DO SOLO, 24., Ribeirão Preto, 2003. Anais. Ribeirão Preto, SBCS/ UNESP, 2003. CD-ROM.

ANJOS, A.R.M. \& MATTIAZZO, M.E. Lixiviação de íons inorgânicos em solos repetidamente tratados com biossólido. R. Bras. Ci. Solo, 24:927-938, 2000.

BASSO, C.J. Dejeto líquido de suínos. II-Perdas de nitrogênio e fósforo por percolação no solo sob plantio direto. Ci. Rural, 35:1305-1312, 2005.

CANELLAS, L.P.; SANTOS, G.A. \& AMARAL SOBRINHO, N.M.B. Reações da matéria orgânica. In: SANTOS, G.A., ed. Fundamentos da matéria orgânica do solo: Ecossistemas tropicais e subtropicais. Porto Alegre, Metrópole, 2008.

DECHEN, A.R. \& NACHTIGALL, G.R. Micronutrientes. In: FERNANDES, M.S., ed. Nutrição mineral de plantas. Viçosa, MG, Sociedade Brasileira de Ciência do Solo, 2006. p.327-354.

EMPRESA BRASILEIRA DE PESQUISA AGROPECUÁRIA EMBRAPA. Serviço Nacional de Levantamento e Conservação de Solos. Manual de métodos de análise de solos. Rio de Janeiro, 1997. 212p.

EMPRESA BRASILEIRA DE PESQUISA AGROPECUÁRIA EMBRAPA. Serviço Nacional de Levantamento e Conservação de Solos. Sistema brasileiro de classificação de solos. 2.ed. Rio de Janeiro, Embrapa Solos, 2006. 306p.
FERREIRA, M.E.; CRUZ, P.M.C.; RAIJ, B.van \& ABREU, C.A. Micronutrientes e elementos tóxicos na agricultura. Jaboticabal, CNPq/FAPESP/POTAFOS, 2001. 600p.

GALRÃO, E.Z. Resposta do trigo à aplicação de cobre em um solo orgânico de várzea. R. Bras. Ci. Solo, 12:275-279, 1988.

GIROTTO, E.; CERETTA, C.A.; BRUNETTO, G.; LOURENZI, C.R.; VIEIRA, R.C.B.; LORENSINI, F. \& TRENTIN, E.E. Acúmulo de cobre e zinco no solo após sucessivas aplicações de dejeto líquido de suínos. In: CONGRESSO BRASILEIRO DE CIÊNCIA DO SOLO, 26., Gramado, 2007. Anais. Gramado, 2007. CD-ROM.

GRÄBER, I.; HANSEN, J.F.; OLESEN, S.E.; PETERSEN, J.; ØSTERGAARD, H.S. \& KROGH, L. Copper and zinc in danish agricultural soils in intensive pig production areas. Danish J. Geogr., 105:15-22, 2005.

KABATA-PENDIAS, A. \& PENDIAS, H. Trace elements in soil and plants. 3.ed. Boca Raton, CRC Press, 2001. $413 p$.

KONZEN, E.A. Manejo e utilização dos dejetos de suínos. Concórdia, Embrapa-CNPSA, 1983. 32p. (EmprapaCNPSA. Circular Técnica)

LAVADO, R.S.; PORCELLI, C.A. \& ALVAREZ, R. Nutrient and heavy metal concentration and distribution in corn, soybean and wheat as affected by different tillage systems in the Argentine Pampas. Soil Tillage Res., 62:55-60, 2001.

LUCHESE, A.V.; GONÇALVES JUNIOR, A.C.; LUCHESE, E.B. \& BRACCINI, M.C.L. Emergência e absorção de cobre por plantas de milho (Zea mays) em resposta ao tratamento de sementes com cobre. Ci. Rural, 34:1949$1952,2004$.

MALAVOLTA, E.; VITTI, G.C. \& OLIVEIRA, S.A. Avaliação do estado nutricional das plantas: Princípios e aplicações. 2.ed. Piracicaba, POTAFOS, 1997. 319p.

MARTINS, A.L.C.; BATAGLIA, O.C.; CAMARGO, O.A. \& CANTARELlA, H. Produção de grãos e absorção de $\mathrm{Cu}, \mathrm{Fe}, \mathrm{Mn}, \mathrm{Zn}$ pelo milho em solo adubado com lodo de esgoto, com e sem calcário. R. Bras. Ci. Solo, 27:563-574, 2003.

MATTIAS, J.L. Metais pesados em solos sob aplicação de dejetos líquidos de suínos em duas microbacias hidrográficas de Santa Catarina. Santa Maria, Universidade Federal de Santa Maria, 2006. 165p. (Tese de Doutorado)

MATOS, A.T.; FONTES, M.P.F.; JORDÃO, C.P. \& COSTA, L.M. Mobilidade e formas de retenção de metais pesados em Latossolo Vermelho-Amarelo. R. Bras. Ci. Solo, 20:379-386, 1996

MARSCHNER, H. Mineral nutrition of higher plants. 2.ed. London, Academic Press, 1995. 889p.

NASCIMENTO, C.W.A.; BARROS, D.A.S.; MELO, E.E.C. \& OLIVEIRA, A.B. Alterações químicas em solos e crescimento de milho e feijoeiro após aplicação de lodo de esgoto. R. Bras. Ci. Solo, 28:385-392, 2004. 
RAIJ, B.van; QUAGGIO, J.A.; CANTARELLA, H.; FERREIRA, M.E.; LOPES, A.S. \& BATAGLIA, O.C. Análise química do solo para fins de fertilidade. Campinas, Fundação Cargill, 1987. 170p.

RAIJ, B.van; SILVA, N.M.; BATAGLIA, O.C.; QUAGGIO, J.A.; HIROCE, R.; CATARELLA, H.; BELLINAZZI JR, R.; DECHEN, A.R. \& TRANI, P.E. Recomendação de adubação e calagem para o Estado de São Paulo. Campinas, IAC, 1996. 285p.

RAPPAPORT, B.D.; MARTENS, D.C.; RENEAU JUNIOR, R.B. \& SIMPSON, T.W. Metal availability in sludge-amended soil with elevated metal levels. J. Environ. Qual., 17:4247,1988 .

REDDY, M.R.; LAMECK, D. \& REZAMOA, M.E. Uptake and distribution of copper and zinc by soybean and corn from soil treated with sewage sludge. Plant Soil, 113:271-274, 1989.

SEGANFREDO, M.A. Efeito de dejetos de suínos sobre o nitrogênio total, amônio e nitratos na superfície do solo. In: REUNIÃO SUL-BRASILEIRA DE CIÊNCIA DO SOLO, 2., Santa Maria, 1998. Anais. Santa Maria, Sociedade Brasileira de Ciência do Solo, 1998. CD-ROM.

SEGANFREDO, M.A. A questão ambiental na utilização de dejetos de suínos como fertilizante do solo. Concórdia, Embrapa Suínos e Aves, 2000. 35p. (Embrapa Suínos e Aves - Circular Técnica, 22)
SIMONETE, M.A. \& KIEHL, J.C. Extração e fitodisponibilidade de metais em resposta à adição de lodo de esgoto no solo. Sci. Agric., 59:555-563, 2002.

SILVA, S.M.C.P.; SOCCOL, V.T.; FERNANDES, F. \& MORITA, D.M. Principais contaminates do lodo. In: von SPERLING, M.; ANDREOLI, C.V. \& FERNANDES, F., eds. Lodo de esgotos: Tratamento e disposição final: Princípios do tratamento biológico de águas residuárias. Belo Horizonte, DESA-UFMG, 2001. v.6. p.319-397.

SILVA, M.L.S.; VITTI, G.C. \& TREVIZAM, A.R. Concentração de metais pesados em grãos de plantas cultivadas em solo com diferentes níveis de contaminação. Pesq. Agropec. Bras., 42:527-535, 2007.

SCHERER, E.E.; BALDISSERA, I.T. \& DIAS, L.F.X. Potencial fertilizante do esterco líquido de suínos da região Oeste Catarinense. Agropec. Catarinense, 8:35-35, 1995.

STEVENSON, F.J. \& ARDAKANI, M.S. Organic matter reactions involving micronutrients in soils. In: MORTVEDT, J.J.; GIORDANO, P.M. \& LINDSAY, W.L., eds. Micronutrients in agriculture. Madison, Soil Science Society of America, 1972. p.79-114.

TEDESCO, M.J.; VOLKWEISS, S.J. \& BOHNEN, H. Análises de solo, plantas e outros materiais. Porto Alegre, Universidade Federal do Rio Grande do Sul, 1995. (Boletim Técnico, 5) 